\title{
Structural, Morphological and Dielectric Studies of Sol Gel Derived Gd Doped $\mathrm{SrTiO}_{3-\delta}$
}

\author{
Ramanjeet Kaur \\ Department of Applied Sciences \\ SBSSTC, I. K. Gujral Punjab Technical University \\ Kapurthala(Punjab), India \\ ramanjeetgill99@gmail.com
}

\author{
Anand K Tyagi \\ Department of Applied Sciences \\ SBS State Technical Campus \\ Firozpur(Punjab), India \\ anandktyagi@gmail.com
}

\begin{abstract}
Gadolinium doped $\mathrm{SrTiO}_{3-\delta}$ i.e. $\mathrm{Sr}_{1-\mathrm{x}} \mathrm{Gd}_{\mathbf{x}} \mathrm{TiO}_{3-\delta}$ for various values of ' $x$ ' have been successfully synthesized using sol gel technique in the reported work. XRD patterns of the obtained ceramics are found to be sharp and well defined having no impurity phases for all the compositions. Lattice parameter ' $a$ ' decreases with increase in the amount of Gadolinium. XRD, FESEM and EDX studies confirm the formation of $\mathrm{Sr}_{1-x} \mathrm{Gd}_{x} \mathrm{TiO}_{3-\delta}$ ceramics with required cubic structure. FESEM/EDX analysis reveals that ceramics possess high density with marginal inter-granular porosity. The dielectric studies show that the synthesized samples possess high dielectric constants, high ac conductivity and low loss factors which further improve with gadolinium doping
\end{abstract}

Keywords—perovskites, morphological, structural, dielectric, sol gel.

\section{INTRODUCTION}

Solid Oxide Fuel cell (SOFC) is one of the leading options available as efficient and environment friendly technologies that can generate power from renewable fuels like hydrogen etc. [1]. The conventional materials e.g. nickel/copper - yttria stablized zirconia, rare earth doped ceria etc., used for the fabrication of different components of SOFCs i.e. anode, cathode and electrolyte; suffer from the various problems like sulfur poisoning, poor mechanical integrity, carbon deposition and lesser stability in reducing conditions. These problems put a major hurdle in commercializing this futuristic technology. The perovskite type oxides, which have a general formula of $\mathrm{ABO}_{3}$, have been the focus of extensive research as these can withstand the aforesaid problems. The most widely studied perovskites are Strontium titanates, Lanthanum chromites and their doped forms [2]. The doping of $\mathrm{SrTiO}_{3-\delta}$ with various elements i.e. $\mathrm{La}, \mathrm{Ce}, \mathrm{Sm}, \mathrm{Gd}, \mathrm{Dy}, \mathrm{Y}, \mathrm{Cu}$ for $\mathrm{Sr}$ site and $\mathrm{Fe}$, $\mathrm{V}, \mathrm{W}, \mathrm{Mo}, \mathrm{Ta}, \mathrm{Nb}$ for $\mathrm{Ti}$ site have been investigated by various research groups and enhancement in the ionic conductivity has been reported [3]. A number of synthesis routes have been employed to synthesize these perovskite materials in literature but all of them suffer from one or the other problems but sol gel based method offers a clean, contamination free and easy technology for synthesizing these materials. In this study, Gd doped $\mathrm{SrTiO}_{3-\delta}$ i.e. $\mathrm{Sr}_{1}$ ${ }_{x} \mathrm{Gd}_{\mathrm{x}} \mathrm{TiO}_{3-\delta}(\mathrm{x}=0,0.05,0.15)$ have been synthesized using sol gel technique and investigated for structural, microstructural, elemental composition and dielectric properties using XRD, FESEM/EDX and Impedance analysis.

\section{EXPERIMENTAL WORK}

\section{A. Synthesis}

$\mathrm{Sr}_{1-\mathrm{x}} \mathrm{Gd}_{\mathrm{x}} \mathrm{TiO}_{3-\delta}(\mathrm{x}=0,0.05,0.15)$ samples have been prepared via sol gel method employing titanium tetra isopropoxide $\quad\left\{\mathrm{Ti}\left(\mathrm{OC}_{3} \mathrm{H}_{7}\right)_{4}\right\}$, strontium acetate $\left\{\mathrm{Sr}\left(\mathrm{CH}_{3} \mathrm{COO}\right)_{2}\right\}$ and gadlonium Nitrate $\left\{\mathrm{Gd}\left(\mathrm{NO}_{3}\right) \cdot 6 \mathrm{H}_{2} \mathrm{O}\right\}$; all from Alfa Aesar ${ }^{\mathrm{TM}}$, as starting chemicals. The propanol, hydrochloric acid $(\mathrm{HCl})$ and distilled water were used as solvents. In all, three samples have been synthesized corresponding to $\mathrm{x}=0,0.05$ and 0.15 and the obtained samples have been termed as STO0, STG05 and STG15 respectively.

$(1-\mathrm{x}) \mathrm{Sr}\left(\mathrm{CH}_{3} \mathrm{COO}\right)_{2}+\mathrm{x} \mathrm{Gd}\left(\mathrm{NO}_{3}\right) \cdot 6 \mathrm{H}_{2} \mathrm{O}+\mathrm{Ti}\left(\mathrm{OC}_{3} \mathrm{H}_{7}\right)_{4} \rightarrow$ $\mathrm{Sr}_{1-\mathrm{x}} \mathrm{Gd}_{\mathrm{x}} \mathrm{TiO}_{3-\delta}$

The required amounts of chemicals were calculated using the above metallurgical reaction. Firstly a $6 \mathrm{wt} \%$ alcoholic solution of titanium dioxide $\left(\mathrm{TiO}_{2}\right)$ was prepared using titanium tetra isopropoxide $(28 \mathrm{wt} \%)$ as precursor, hydrochloric acid $(13 \mathrm{wt} \%)$ as catalyst, propanol $(58 \mathrm{wt} \%)$ and distilled water $(1 \mathrm{wt} \%)$ as solvent. A part of propanol was mixed with titanium tetra isopropoxide to form a solution (1) and the remaining amount of propanol, distilled water \& $\mathrm{HCl}$ were mixed to form a solution (2). Both the solutions $(1 \& 2)$ were kept stirring at room temperature for 20 minutes and were then mixed to form the alcoholic solution. The alcoholic solution was stirred at room temperature for 24 hours and then calculated amounts of strontium acetate $\left\{\mathrm{Sr}\left(\mathrm{CH}_{3} \mathrm{COO}\right)_{2}\right\}$ and $\mathrm{Gd}\left(\mathrm{NO}_{3}\right) \cdot 6 \mathrm{H}_{2} \mathrm{O}$ were added to it to prepare the titania solution. The prepared solution was kept for 2-3 hours at room temperature, as a result of which the destabilized titania solution turned to homogeneous opalescent alcogel. The alcogel was then dried at $\sim 80^{\circ} \mathrm{C}$ and crushed to obtain the fine powder [4]. The obtained powders were calcined at $600^{\circ} \mathrm{C}$ and then sintered at $1250^{\circ} \mathrm{C}$ for 2 hours at heating rate $3^{\circ} \mathrm{C}$ per minute. The pellets of the sintered powders were prepared and calcined at $600^{\circ} \mathrm{C}$ for 1 hour at heating rate of $3^{\circ} \mathrm{C}$ per minute to expel the binder. The sintering was done before the pellet formation to avoid the pulverization of pellets. All the three samples were prepared using the aforesaid technique in a single go.

\section{B. Characterization}

$\mathrm{X}$ ray diffraction analysis of the prepared pellets was carried out with the help of XPERT-PRO X-RAY diffractometer 0000000011141934 using $\mathrm{Cu} \mathrm{K} \alpha$ radiation. SEM/EDX analysis was done using using Nova Nano FESEM (FEI) for morphological and elemental analysis. The 
dielectric properties of the sintered the samples were studied with the help of LCR HiTester.

\section{RESULTS AND DISCUSSION}

\section{A. XRD Characterization}

The XRD patterns for $\mathrm{Sr}_{1-\mathrm{x}} \mathrm{Gd}_{\mathrm{x}} \mathrm{TiO}_{3-\delta}$ samples $(0 \leq x \leq 0.15)$ are shown in fig. 1 . Clearly, all the XRD peaks are well defined and can be indexed on the basis of cubic symmetry of the structure [5]. The XRD patterns observed are similar to the XRD pattern of $\mathrm{SrTiO}_{3}$ reported in literature [4]. All Gd doped $\mathrm{Sr}_{1-\mathrm{x}} \mathrm{Gd}_{\mathrm{x}} \mathrm{TiO}_{3-\delta}$ samples show nearly identical XRD patterns with no detectable impurity phases. However, the peaks show a shift toward larger angle side which may be attributed to intake of relatively smaller ion $\mathrm{Gd}^{3+}(107.8 \mathrm{pm})$ as a replacement of $\mathrm{Sr}^{2+}(132 \mathrm{pm})$ ions in the ceramic matrix. The shift in the angle with variation in value of $x$ for most intense peak (110) has been shown in fig. $2[6,7]$.

The indexing of peaks and calculation of lattice parameters are done using the mathematical method for cubic crystals [5]. The lattice parameters ' $\mathrm{a}$ ' values for $\mathrm{Sr}_{1-\mathrm{x}} \mathrm{Gd}_{\mathrm{x}} \mathrm{TiO}_{3-\delta}$ sample $(0 \leq x \leq 0.15)$ are $3.9113,3.9083$ and $3.8972 \AA$ for $x=0$, $\mathrm{x}=0.05$ and $\mathrm{x}=0.15$ respectively. The variation of lattice parameter ' $a$ ' with variation in amount of gadolinium is given in the fig. 3 . The parameter is found to decrease with the increase in amount of Gadolinium. This is due to the replacement of $\mathrm{Sr}^{2+}(132 \mathrm{pm})$ ions with smaller $\mathrm{Gd}^{3+}(107.8$ pm) ions [6].

The crystallite sizes as calculated for (110) reflection for $\mathrm{Sr}_{1-\mathrm{x}} \mathrm{Gd}_{\mathrm{x}} \mathrm{TiO}_{3-\delta}$ samples $(0 \leq \mathrm{x} \leq 0.15)$ using Sherrer's equation [8] are 46.710, 46.714 and $46.723 \mathrm{~nm}$ for ST0, STG05 and STG15 respectively; clearly in nano range.

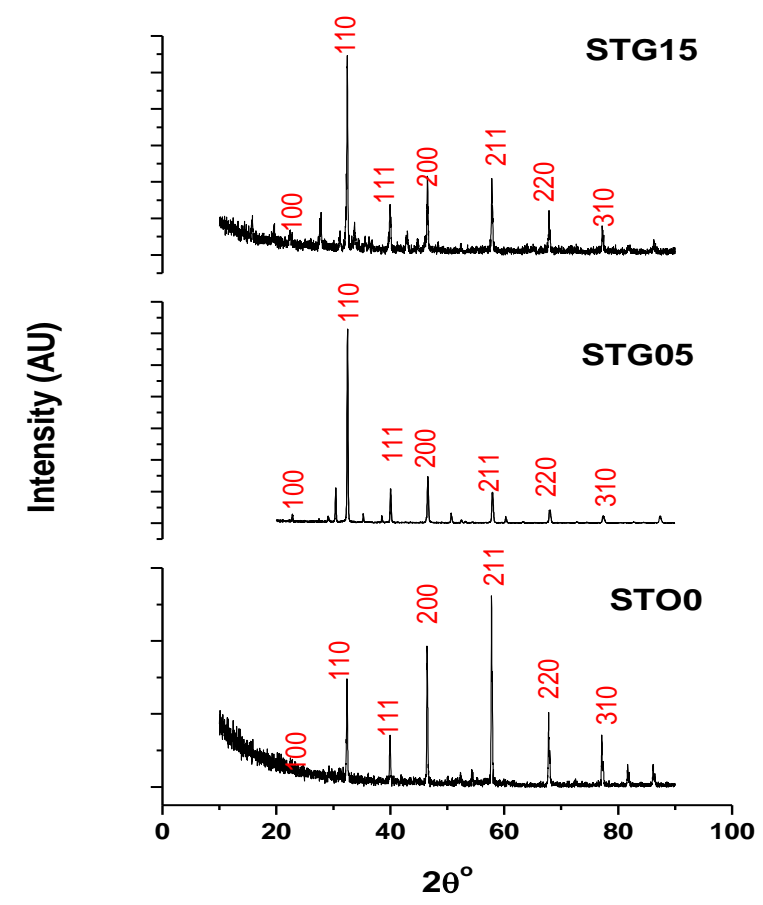

Fig. 1. XRD peak pattern for $\mathrm{Sr}_{1-\mathrm{x}} \mathrm{Gd}_{\mathrm{x}} \mathrm{TiO}_{3-\delta}(0 \leq \mathrm{x} \leq 0.15)$ samples.

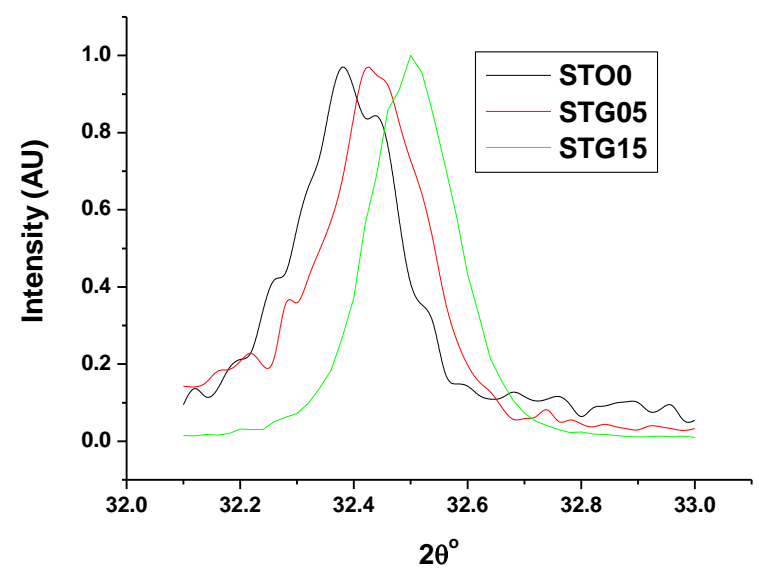

Fig. 2. Shift of most intense peak (110) of $\operatorname{Sr}_{1-\mathrm{x}} \mathrm{Gd}_{\mathrm{x}} \mathrm{TiO}_{3-\delta}(0 \leq \mathrm{x} \leq 0.15)$ samples with increase in value of $\mathrm{x}$.

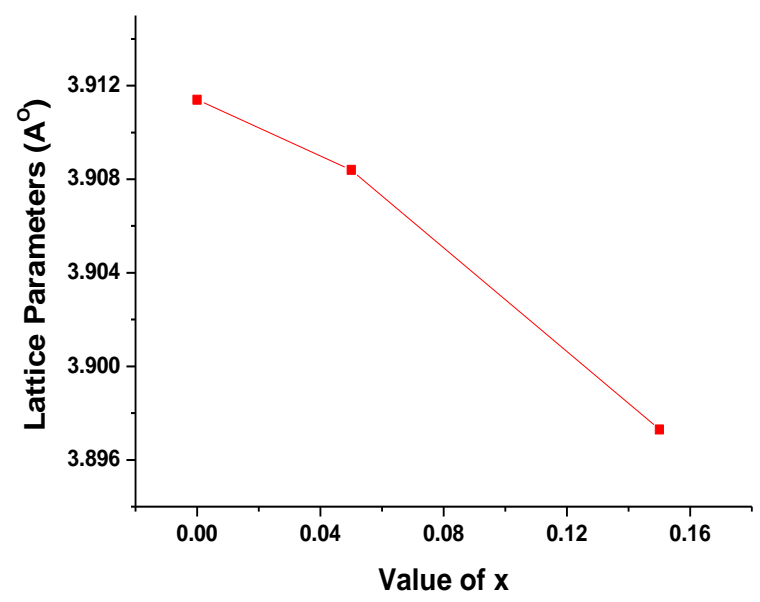

Fig. 3. Variation of lattice parameter of $\mathrm{Sr}_{1-\mathrm{x}} \mathrm{Gd}_{\mathrm{x}} \mathrm{TiO}_{3-\delta}$ sample $(0 \leq \mathrm{x} \leq 0.15)$ with $\mathrm{x}$

\section{B. FESEM Analysis}

The microstructures of all $\mathrm{Sr}_{1-\mathrm{x}} \mathrm{Gd}_{\mathrm{x}} \mathrm{TiO}_{3-\delta} \quad(0 \leq \mathrm{x} \leq 0.15)$ samples as obtained by FESEM are shown in fig. 4. Clearly, all the samples are dense having homogeneous microstructure with well developed small angular grains. The grains have isotropic shapes close to spherical one for STO0 $(x=0)$ whereas it is cubiodal for STG05; $x=0.05$ and polyhedral for STG15; $\mathrm{x}=0.15$ samples. The grain boundaries for all the prepared samples are smooth and clear having straight edges, well defined corners, faces without any extra phase precipitation. The straight edges confirm the high crystalline nature of the obtained ceramics, similar also revealed by XRD analysis. The synthesized $\mathrm{Sr}_{1-\mathrm{x}} \mathrm{Gd}_{\mathrm{x}} \mathrm{TiO}_{3-\delta}$ $(0 \leq x \leq 0.15)$ samples have good sinterabiltiy and the low amount of inter-granular porosity as indicated by few residual and isolated voids present in the micrographs of these samples. It is worth noting that the low heating rate used in the experiment i.e. $3^{\circ} \mathrm{C} / \mathrm{min}$ for sintering is favorable to the grain growth. 


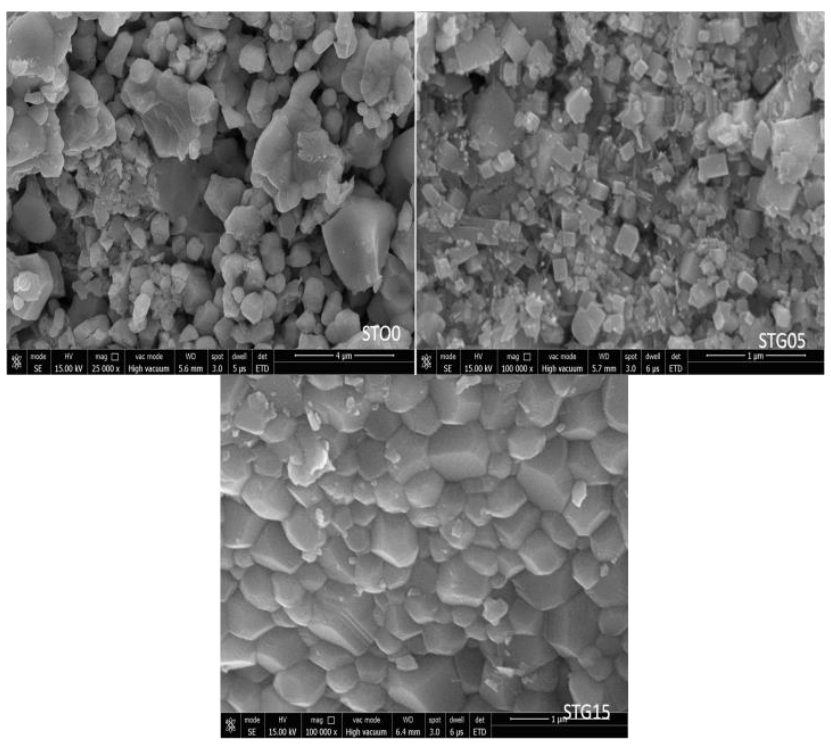

Fig. 4. FESEM Image of $\mathrm{Sr}_{1-\mathrm{x}} \mathrm{Gd}_{\mathrm{x}} \mathrm{TiO}_{3-\delta}$ samples for $(0 \leq \mathrm{x} \leq 0.15)$

The microstructures of $\quad \mathrm{Sr}_{1-\mathrm{x}} \mathrm{Gd}_{\mathrm{x}} \mathrm{TiO}_{3-\delta} \quad(0 \leq \mathrm{x} \leq 0.15)$ samples have almost identical features, differing only in grain sizes. The grain sizes for $\mathrm{SrTiO}_{3-\delta}$ samples as obtained from FESEM analysis are in the range 407-972 nm, 86.38 $\mathrm{nm}$ to $269.0 \mathrm{~nm}$ and $193.1 \mathrm{~nm}$ to $633.1 \mathrm{~nm}$ for STO0, STG05 and STG15 respectively; clearly in the nano range. The grain sizes of the synthesized samples are smaller than reported in the literature; that is normally in the micrometer range for the rare earth doped $\mathrm{SrTiO}_{3}$ ceramics prepared by other techniques e.g. at high sintering temperature $~ 1300$ $1470^{\circ} \mathrm{C}[7,9]$. The nano size of the synthesized samples may be due to the fine precursor powders derived from solgel method and the low densification sintering temperature.

The grain growth in $\mathrm{SrTiO}_{3-8}$ has been reported to be highly sensitive to doping amount $[7,10]$. Here also, it can be easily realized that increase in Gadolinium doping leads to decrease in the grain size. Thus, the high purity rare earth doped $\mathrm{SrTiO}_{3-\delta}$ materials with high density have been successfully obtained by sol gel process at relatively lower sintering temperature.

\section{EDX Analysis}

From the analysis of EDX spectra for all the compositions of $\mathrm{Sr}_{1-\mathrm{x}} \mathrm{Gd}_{\mathrm{x}} \mathrm{TiO}_{3-\delta}$ samples, it was found that in STO0; $\mathrm{x}=0$ sample, strontium, titanium and oxygen elements are present whereas in STG05; $x=0.05$ and STG15; $x=0.15$ along with these, gadolinium is also present as expected. No any other element is found in the spectra clearly indicating the purity of phase for the synthesized $\mathrm{Sr}_{1-\mathrm{x}} \mathrm{Gd}_{\mathrm{x}} \mathrm{TiO}_{3-\delta}$ samples.

TABLE I. ATOMIC RATIO FOR STO0, STG05 AND STG15 SAMPLES

\begin{tabular}{|l|l|l|l|l|l|}
\hline & \multicolumn{1}{|c|}{$\mathbf{x}$} & \multicolumn{1}{|c|}{ Sr } & \multicolumn{1}{|c|}{ Gd } & \multicolumn{1}{|c|}{ Ti } & \multicolumn{1}{|c|}{$\mathbf{0}$} \\
\hline ST00 & 0 & 1.26 & 0 & 1 & 3.29 \\
\hline STG05 & 0.05 & 1.07 & 0.08 & 1 & 2.67 \\
\hline STG15 & 0.15 & 0.79 & 0.18 & 1 & 3.71 \\
\hline
\end{tabular}

It can be easily depicted from atomic ratio of the elements given in table 1 for $\mathrm{Sr}_{1-\mathrm{x}} \mathrm{Gd}_{\mathrm{x}} \mathrm{TiO}_{3-\delta}$ samples $(0 \leq x \leq 0.15)$ that amount of gadolinium increases with increase in the value of ' $x$ ' as expected while that of strontium decreases.

\section{Dilelectric characterization}

The values of dielectric constant $\left(\varepsilon_{\mathrm{r}}\right)$ were determined from the measured values of capacitance using the LCR meter between $30-400^{\circ} \mathrm{C}$ temperatures. The frequency dependence of $\varepsilon_{\mathrm{r}}$ at room temperature is shown in fig. 5 for pure STO0 sample. The variations of dielectric constant with temperature ranging from 50 to $400^{\circ} \mathrm{C}$ at frequencies $10 \mathrm{KHz}$, and $100 \mathrm{KHz}$ for STO0 sample is shown in fig. 6 . A sharp decrement in $\varepsilon_{\mathrm{r}}$ values with increase in frequency $(<1 \mathrm{kHz})$ can be observed which may be due to the reason that at low frequency, contribution from electronic, ionic, orientation and space charge polarization exist but at high frequency only electronic polarization or some contribution from ionic polarization [11]. The strong dependence of dielectric constant on frequency up to $1 \mathrm{KHz}$ is evident from fig. 5; which is termed as dielectric dispersion [12] and is quite common for dielectric materials. Whereas dielectric constant remains almost constant at frequencies above 1 $\mathrm{KHz}$ which is due to the reason that electric dipoles can't follow the fast varying electric field.

The dielectric constant remains almost constant up to a certain temperature and then, increases rapidly with increasing temperature $\left(300-400^{\circ} \mathrm{C}\right)$ from fig. 6 . The space charge polarization arising from the movement of ions and defects in the material may be responsible for this increase [13]. There is no curie peak detected in the whole measurement temperature range [14-15]. The high values of dielectric constant at room temperature for STO0 sample may be attributed to the presence of all kinds of polarizations at room temperature which can lead to irregular increase in the permittivities [16-17]. Gd doped samples i.e STG05 and STG15 had same dielectric variation trends as the pure STO0 sample but larger dielectric constant values at all the studied temperatures and frequencies $[18,19]$.

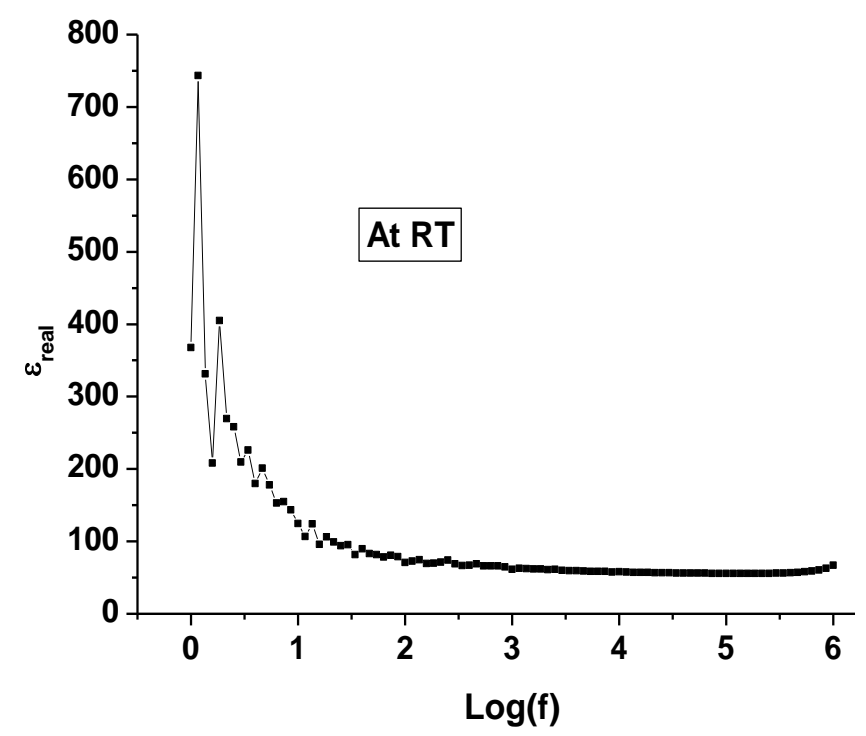

Fig. 5. Variation of dielectric constant with frequency at room temperature for STOO $(x=0)$ 


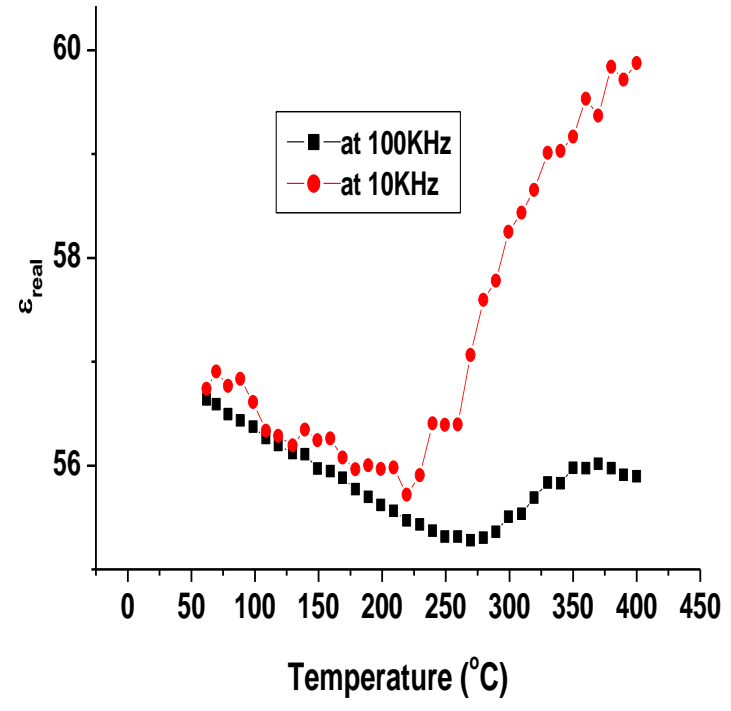

Fig. 6. Variation of dielectric constant with temperature at $10 \mathrm{KHz}$ and $100 \mathrm{~K} \mathrm{~Hz}$ for $\mathrm{SrTiO}_{3}$

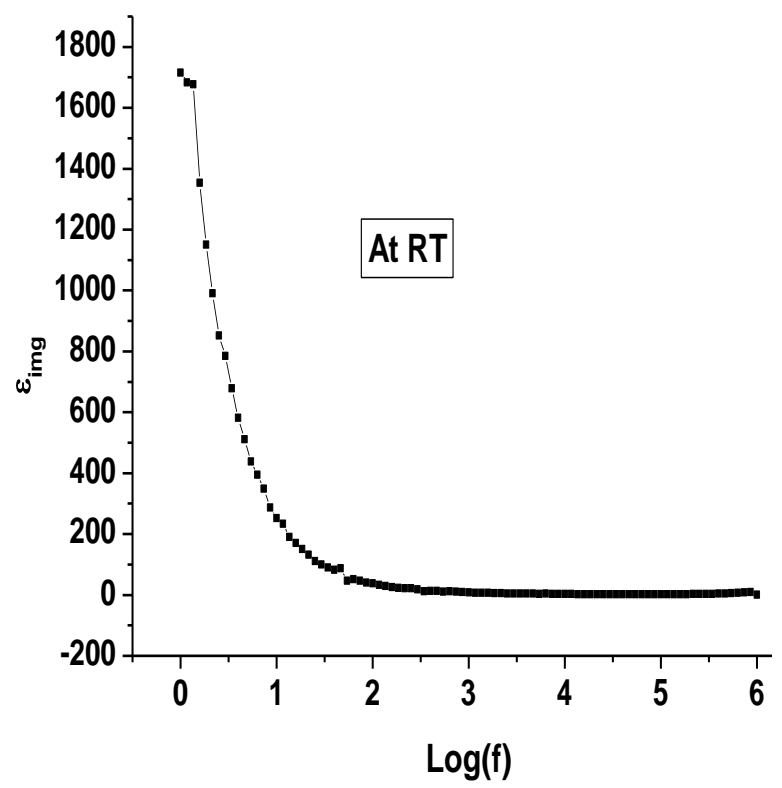

Fig. 7. Variation of imaginary part of dielectric constant with frequency at room temperature for $\mathrm{SrTiO}_{3}$

Fig. 7 show the frequency dependence of imaginary dielectric constant $\left(\varepsilon^{\prime \prime}\right)$ for pure $\mathrm{SrTiO}_{3}$ (STO0) sample. $\varepsilon^{\prime \prime}$ shows the similar trends as that of $\varepsilon_{\mathrm{r}}$ i.e. increase with temperature and decrease with frequency. There is no loss peak in the whole frequency spectrum of $\varepsilon^{\prime \prime}$. The values of $\varepsilon^{\prime \prime}$ are high only at low frequencies (below $1 \mathrm{KHz}$ ) and at high temperature $\left(300^{\circ} \mathrm{C}\right.$ to $\left.400^{\circ} \mathrm{C}\right)$ owing to the interfacial build up of the free charges either within the sample (Maxwell-Wagner (MW) polarization) [20] or between sample and the electrodes (space-charge polarization). It was observed that doping leads to increase in imaginary component of dielectric constant.

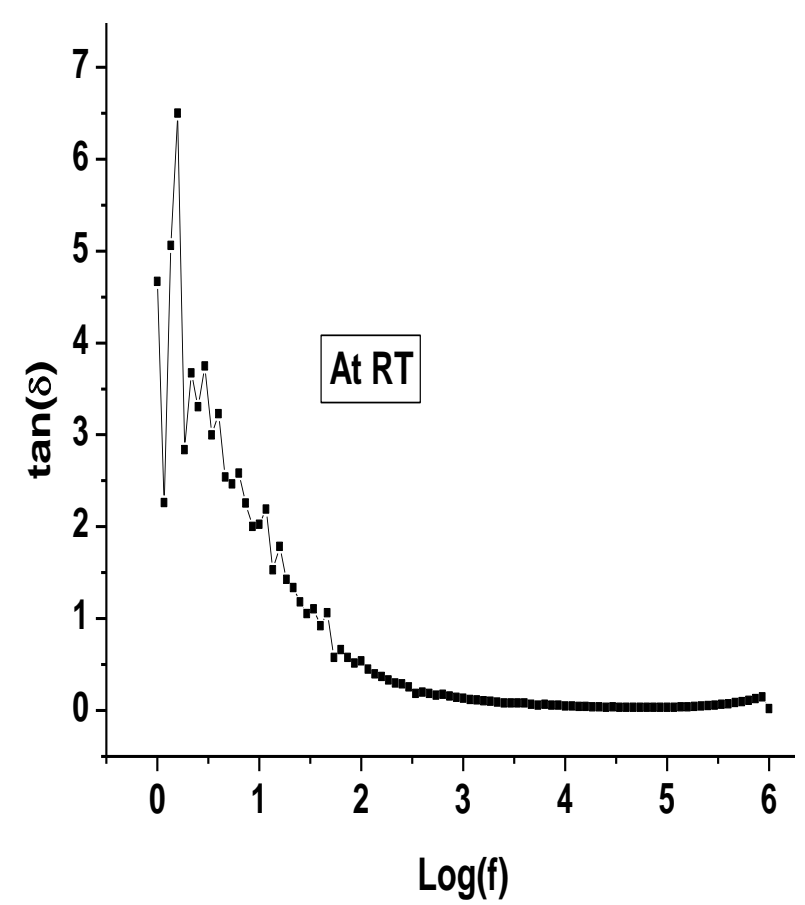

Fig. 8. Variation of loss tangent with frequency at room temperature for $\mathrm{SrTiO}_{3}$

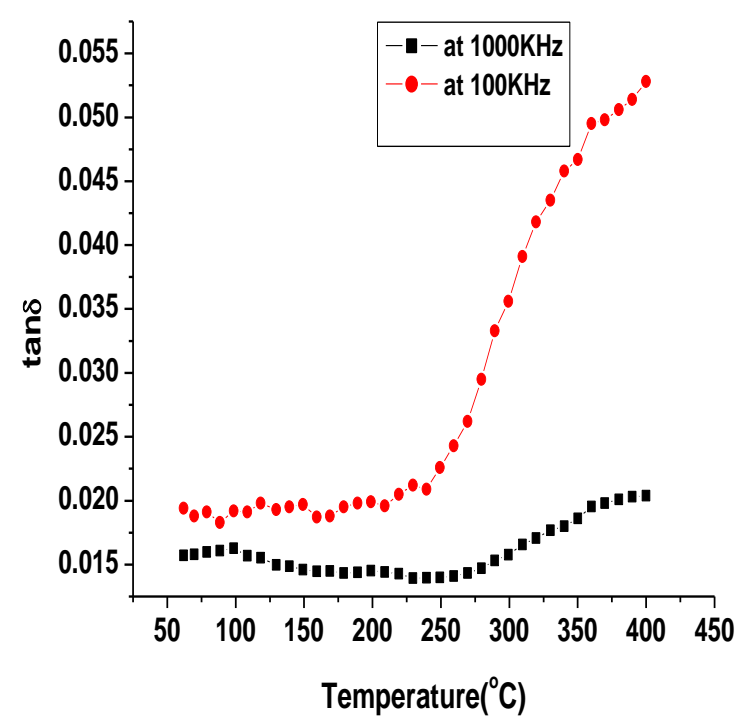

Fig. 9. Variation of loss tangent with temperature at various temperatures for $\mathrm{SrTiO}_{3}$

The variation of loss tangent for STO0 sample with frequency at room temperature is shown in fig. 8. Fig. 9 depicts the dependence of dielectric loss on temperature at frequencies $1000 \mathrm{KHz}$ and $100 \mathrm{KHz}$ from 50 to $400^{\circ} \mathrm{C}$. From all these plots, it can be easily observed that $\tan \delta$ values decrease with frequency and increase with temperature. The decrease of dielectric loss with frequency can be explained using the relation $\tan \delta \propto \sigma \backslash 2 \Pi f$, where $\tan \delta$ is the loss tangent factor, $\sigma$ is the conductivity and $f$ is the frequency [21]. The increase in frequency is more than the increase in conductivity with frequency. So, loss tangent 
factor shows a decrease with the increase in frequency within the entire temperature range.

The observed enhancement in loss factor values at high temperature can be due to transportation of thermally energetic ions. The conductivity dominates at high temperatures due to presence of oxygen vacancies and defects created by oxygen loss at high temperature sintering; which leads to increase in loss factor also. In spite of this, the ferroelectric domain walls contribute less at high temperature leading to rise in loss tangent factor. Similar dielectric behavior has been reported in the literature for similar category compounds $[14,15,17,18]$. The variation trends for the doped samples were approximately identical to that for undoped STO0. However an increase in loss factor was observed with doping [22].

The frequency dependence of ac conductivity at room for undoped STO0 sample is shown in fig. 10. Fig. 11 depicts the temperature dependence of ac conductivity at 10 $\mathrm{KHz}$ and $100 \mathrm{KHz}$ frequency. It can be easily depicted that ac conductivity is almost constant at lower frequencies; while at higher temperatures and frequencies there is a sharp enhancement in ac conductivity due to the strong hopping mechanism [23]. A plateau in the curves at low frequency and dispersion at high frequencies can be easily observed in the spectra. The conductivity which corresponds to the plateau region, is independent of frequency, and is termed as the DC conductivity. The transportation of the mobile ions due to applied field may be responsible for the observed plateau [24]. The observed trends for doped samples and pure STO0 sample were similar. It was observed that doping with gadolinium gives rise to increase in ac conductivity in comparison to undoped STO0 sample. Similar trends were observed for yttrium or lanthanum doped strontium titanate, where conductivity showed an increase with increasing the doping amount [25].

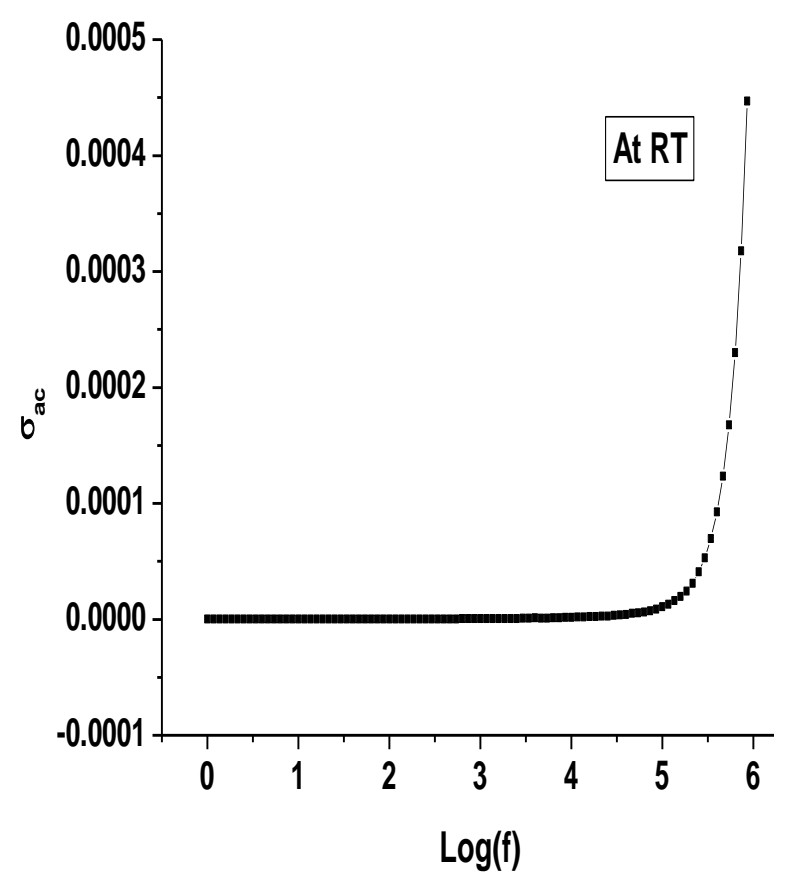

Fig. 10. Variation of ac conductivity with frequency at room temperature for pure STO0 sample.

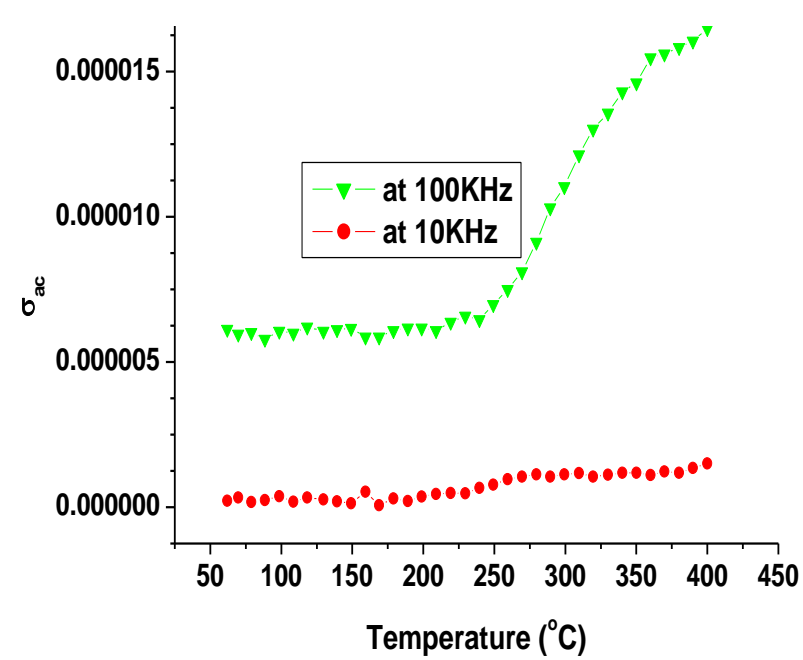

Fig. 11. Variation of ac conductivity with temperature for pure STO0 sample.

Fig. 12 shows the variation of the real part of impedance (Z') for pure STO0 sample with frequency at room temperature, $108,209,309$ and $400^{\circ} \mathrm{C}$ respectively. The decrement in $Z$ ' with frequency as well as with temperature can be easily depicted from the figure. The value of $Z^{\prime}$ for all temperatures coincides at high frequency. All the doped samples show behavior similar to pure STO0 sample. The rise in temperature reduces the barrier which in turn leads to increase in ac conductivity and thus decrement in $Z^{\prime}$. The decrease in $Z^{\prime}$ with rise in temperature is very clear at low frequencies in fig. 12; revealing that synthesized materials possesses negative temperature coefficient of resistance.

Fig. 13 shows the frequency dependence of imaginary part of impedance $\left(Z^{\prime \prime}\right)$ for pure STO sample at various temperatures. It can be easily depicted from the curves that $Z^{\prime \prime}$ values show a maximum value i.e. a peak in the plot; and this peak or maxima shifts towards high frequency value as the temperature is increased. The observed broadening of peaks in these plots may be attributed to spread of relaxation time i.e. the temperature dependence of electrical relaxation in the studied materials. $Z^{\prime \prime}$ values merge in the high frequency region, as clearly visible from the plots; this can be due to accumulation of space charges in the sample [24, $26,27]$

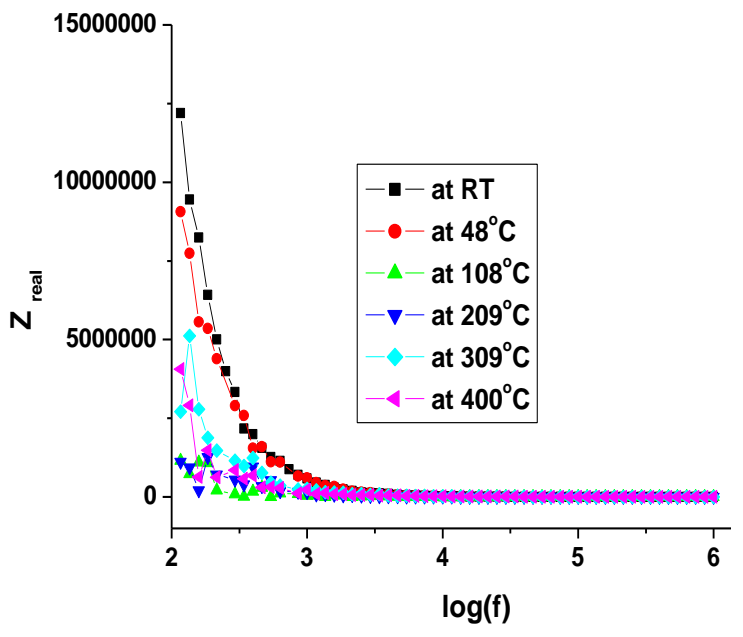

Fig. 12. Variation of real part of impedance with frequency at room temperature and at higher tempertaures for pure STO0 sample. 


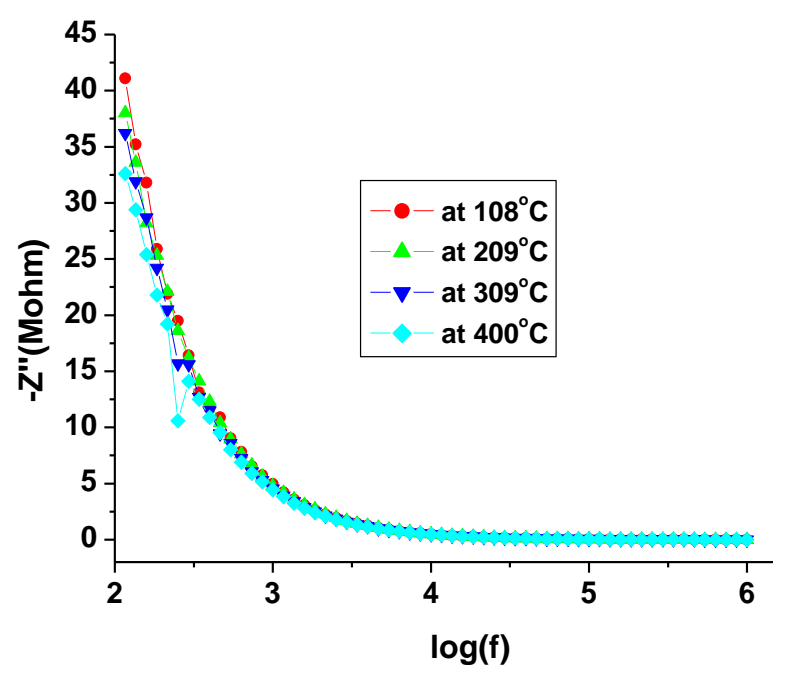

Fig. 13. Variation of imaginary part of impedance with frequency at various temperatures for STO0 sample.

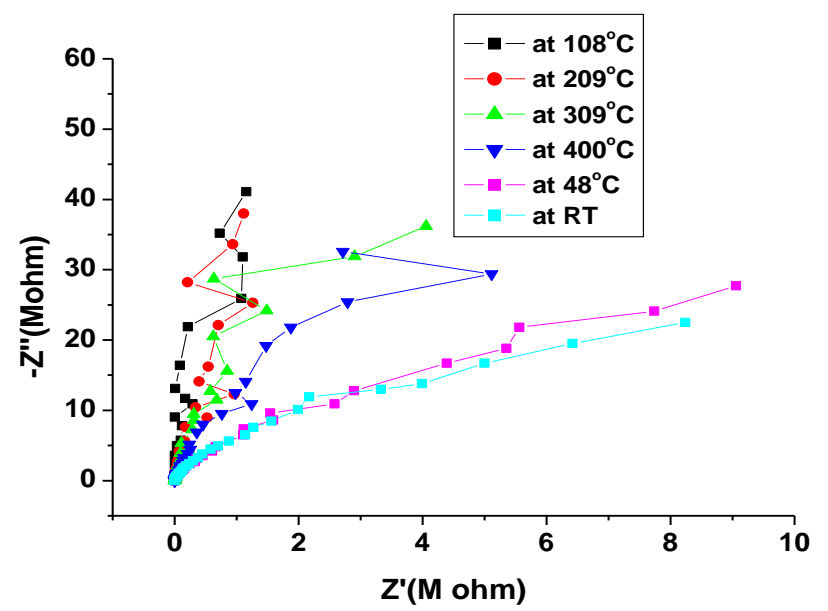

Fig. 14. Cole cole plots between real and imaginary part of impedance at room and other higher temperatures for STO0 sample.

Cole-Cole plots can be used to explain the dielectric relaxation phenomenon within the studied frequency range. Fig. 14 shows the Cole-Cole plots (Nyquist plots) of STO0 ceramic sample at room and other higher temperatures. The presence of single depressed semicircle can be easily depicted from the plots for the studied sample at all temperatures; which represents the grain effect in the synthesized material. Furthermore, the increase in temperature leads to decrease in the semicircle radius indicating the decrement in the resistivity. The behavior of doped samples is similar to that of undoped STO0 sample [26].

\section{CONCULUSIONS}

In this work, $\mathrm{Sr}_{1-\mathrm{x}} \mathrm{Gd}_{\mathrm{x}} \mathrm{TiO}_{3-\delta}(\mathrm{x}=0,0.05$ and $\mathrm{x}=0.15)$ samples have been successfully synthesized using low temperature sol gel technique. The XRD patterns for all the compositions are sharp and well defined having no impurity phases. The lattice parameter decreases with increase in amount of Gadolinium. The microstructures of the synthesized STO0 and STG samples are homogeneous, less porous and crystalline having nanometric grains. The doping with Gadolinium further reduces the grain size. EDX analysis suggested that the ratio of strontium, titanium, gadolinium and oxygen is in close agreement with theoretical values. Thus, XRD and FESEM/EDX studies reveal the formation of phase pure $\mathrm{Sr}_{1-\mathrm{x}} \mathrm{Gd}_{\mathrm{x}} \mathrm{TiO}_{3-\delta}$ samples having cubic structure. All the synthesized samples possess high dielectric constants, high ac conductivity and low loss factors. The dielectric properties show further enhancement with increase in content of gadolinium.

\section{ACKNOWLEDGMENT}

One of the authors Ms. Ramanjeet Kaur highly acknowledges Inder Kumar Gujral Punjab Technical University, Kapurthala, for its valuable inputs in course of this work. The authors are also very thankful to TEQIP, MHRD/World Bank Project for facilitating the necessary research requirements. Furthermore, authors appreciatively acknowledge IIC, I.I.T. Roorkee, MRC, MNIT Jaipur and S B S State Technical Campus, Ferozepur for support in characterization of samples.

\section{REFERENCES}

[1] N. Q. Minh, J. Am. Ceram. Soc., vol. 76, pp. 563, 1993.

[2] R. Mukundan, E. L. Brosha, and F. H. Garzon, Electrochem. SolidState Lett., vol.7, pp. A5-A7, 2004.

[3] L. Zhang, T. Tosho, N. Okinaka, and T. Akiyama, Mater. Trans, vol.48, pp. 2088-2093, 2007.

[4] A. Rocca, A. Licciulli, M. Politi, and D. Diso, "Rare Earth-Doped $\mathrm{SrTiO}_{3}$ Perovskite Formation from Xerogels" International Scholarly Research Network Ceramics, 2012.

[5] Laboratory Module 1, Indexing X-Ray Diffraction Patterns.

[6] R. D. Shannon, Acta Cryst., vol.A 32, pp. 751-767, 1976.

[7] L. Zhang, T. Tosho, N. Okinaka, and T. Akiyama, "Thermoelectric Properties of Combustion Synthesized and Spark Plasma Sintered $\mathrm{Sr}_{1-}$ ${ }_{x} \mathrm{R}_{\mathrm{x}} \mathrm{TiO}_{3}(\mathrm{R}=\mathrm{Y}, \mathrm{La}, \mathrm{Sm}, \mathrm{Gd}, \mathrm{Dy}, 0<\mathrm{x}<0.1)$ ", Mater. Trans., vol. 48, No. 8, pp. 2088-2093, 2007.

[8] B. D. Cullity, Elements of X-Ray Diffraction, 2nd ed., AddisonWesley, 1978

[9] H. C. Wang, W. C. Lei, W. B. Su, J. Liu, Y. Sun, H. Peng, and L. M. Mei, J. Am. Ceram. Soc., vol. 94, pp. 838-842, 2011.

[10] M. V. Makarovaa, A. Artemenkoa, J. Kopecek, F. Laufek, P. Zemenovaa, V. A. Trepakov, and A. Dejnekaa, Scr. Mater., vol.116, pp. 21-25, 2016.

[11] A. Verma, O. P. Thakur, C. Prakash, T. C. Goel, and R. G. Mendiratta, "Temperature dependence of electrical properties of nickel- zinc ferrites processed by the citrate precursor technique", Mater. Sci. Eng. B, vol.116, no.1, 2005.

[12] T. Badapanda, R. K. Harichandan, A. Mishra, and S. Anwar, "Relaxor ferroelectric behavior of $\mathrm{BaBi}_{4} \mathrm{Ti}_{4} \mathrm{O}_{15}$ aurivillius ceramic", J. Adv. Dielectr., vol.3, no.2, pp.1350013, 2013.

[13] P. Abhijit, and B. Amitabha, "Structural, dielectric and electrical properties of lithium silicate ceramics: A comparative study", J. Mater. Sci.: Mater. Electron., vol.24, pp.1855-1862, 2013.

[14] N. F. Muhamad, R. A. M. Osman, M. S. Idris, and M. N. M. Yasin, "Physical and electrical properties of $\mathrm{SrTiO}_{3}$ and $\mathrm{SrZrO}_{3}$ ", EPJ Web Conf., vol.162, pp.01052, 2017.

[15] W. Li, Z. Ma, L. Gao, and F. Wang, "Preparation and Electrical Properties of $\mathrm{La}_{0.9} \mathrm{Sr}_{0.1} \mathrm{TiO}_{3+\delta}$ ", Materials, vol.8, pp.1176-1186, 2015.

[16] X. Wang, B. Zhang, L. Xu, Y. Hu, G. Shen, and L. Sun, "Dielectric properties of $\mathrm{Y}$ and $\mathrm{Nb}$ co-doped $\mathrm{TiO}_{2}$ ceramics", Sci. Rep., vol.7, pp.8517, 2017.

[17] A. Ray, B. Behera, T. Basuy, S. Vajandarz, S. K. Satpathy, and Nayak, "Modification of structural and dielectric properties of polycrystalline Gd-doped BFO-PZO”, J. Adv. Dielectr., vol.8, no.5, pp.1850031, 2018. 
[18] S. K. Rout, S. Panigrahi, and J. Bera, "Characterization of Ni-doped $\mathrm{SrTiO}_{3}$ ceramics using impedance spectroscopy", Indian J. Pure Ap. Phy., vol.42, pp. 741-744, 2004.

[19] S. A. Kumar, and K. C. B. Naidu, "Structural and Dielectric Properties of $\mathrm{Bi}_{2} \mathrm{O}_{3}$ Doped $\mathrm{SrTiO}_{3}$ Ceramics", Int. J. ChemTech Res., vol.9, no.01, pp.58-63, 2016.

[20] S. Kumar, and K. B. R. Varma, "Relaxor behavior of $\mathrm{BaBi}_{4} \mathrm{Ti}_{3} \mathrm{Fe}_{0.5} \mathrm{Nb}_{0.5} \mathrm{O}_{15}$ ceramics", Solid State Commun., vol.147, pp.457-460, 2008.

[21] M. A. White, Physical Properties of Materials, CRC Press: Boca Raton, FL, USA, 2011.

[22] B. Prijamboedi, H. Takashima, R. Wang, A. Shoji, and M. Itoh, "Large dielectric constant arising from space-charge polarization in a $\mathrm{SrTiO}_{3}$ thin film grown on an $\mathrm{YBa}_{2} \mathrm{Cu}_{3} \mathrm{O}_{7-\delta}$ layer", Phys. Status Solidi (a), vol.202, no.14, pp.R152-R154, 2005.
[23] K. C. B. Naidu, T. S. Sarmash, and T. Subbarao, "Synthesis and Characterization of $\mathrm{Mn}$ doped $\mathrm{SrTiO}_{3}$ ceramics", Int. J. Eng. Res. Technol., vol. 3, no.1, 2014.

[24] T. Badapanda, R. K. Harichandan, A. Mishra, and S. Anwar, "Frequency and temperature dependence behaviour of impedance, modulus and conductivity of $\mathrm{BaBi}_{4} \mathrm{Ti}_{4} \mathrm{O}_{15}$ Aurivillius ceramic", Process. Appl. Ceram., vol.8, no.3, pp.145-153, 2014.

[25] J. Karczewski, B. Riegel, M. Gazda, P. Jasinski, and B. Kusz, "Electrical and structural properties of $\mathrm{Nb}$-doped $\mathrm{SrTiO}_{3}$ ceramics", J. Electroceram., vol. 24, pp.326-330, 2010.

[26] S. Sahoo, U. Dash, S. K. S. Parashar, and S. M. All, "Frequency and temperature dependent electrical characteristics of $\mathrm{CaTiO}_{3}$ nanoceramic prepared by high-energy ball milling", J. Adv. Ceram., vol.2, no.3, pp.291-300, 2013.

[27] A. V. Murugan, S. C. Navale, and V. Ravi, "Preparation of nanocrystalline ferroelectric $\mathrm{BaBi}_{4} \mathrm{Ti}_{4} \mathrm{O}_{15}$ by Pechini method", Mater. Lett., vol.60, pp.1023-1025, 2006.

\section{Creative Commons Attribution License 4.0} (Attribution 4.0 International, CC BY 4.0)

This article is published under the terms of the Creative Commons Attribution License 4.0 https://creativecommons.org/licenses/by/4.0/deed.en_US 